This item was submitted to Loughborough's Research Repository by the author.

Items in Figshare are protected by copyright, with all rights reserved, unless otherwise indicated.

\title{
Fabricating porous poly(lactic acid) fibres via electrospinning
}

PLEASE CITE THE PUBLISHED VERSION

https://doi.org/10.1016/j.eurpolymj.2017.12.025

\section{PUBLISHER}

(c) Elsevier

\section{VERSION}

AM (Accepted Manuscript)

\section{PUBLISHER STATEMENT}

This work is made available according to the conditions of the Creative Commons Attribution-NonCommercialNoDerivatives 4.0 International (CC BY-NC-ND 4.0) licence. Full details of this licence are available at: https://creativecommons.org/licenses/by-nc-nd/4.0/

\section{LICENCE}

CC BY-NC-ND 4.0

\section{REPOSITORY RECORD}

Huang, Chao, and Noreen L. Thomas. 2018. "Fabricating Porous Poly(lactic Acid) Fibres via Electrospinning". figshare. https://hdl.handle.net/2134/32251. 


\title{
Fabricating Porous Poly(lactic acid) Fibres via Electrospinning \\ C Huang and N L Thomas* \\ Department of Materials, Loughborough University, Ashby Road, Loughborough, Leicestershire, LE11 3TU, UK *N.L.Thomas@lboro.ac.uk, Tel. +44(0)1509223334
}

\begin{abstract}
In this paper, amorphous poly(lactic acid) (PLA), a biodegradable polymer with excellent biocompatibility, is successfully electrospun into micron-sized fibres with controlled surface and internal morphologies. By careful solvent selection, either surface porosity or internal porosity can be achieved through different mechanisms. Use of chloroform as the solvent gives rise to circular pores of $100 \mathrm{~nm}$ diameter confined to the surface. These are obtained in humid conditions by the so-called 'Breath Figure' mechanism. It is found that combining chloroform with a water-miscible non-solvent yields either surface porosity (wrinkled effect) using a low boiling point liquid, e.g. ethanol, or internal porosity using a high boiling point liquid, e.g. dimethyl sulphoxide (DMSO). Both these microstructures are obtained through a non-solvent induced phase separation (NIPS) mechanism. Finally, it is found possible to produce both surface and internal porosity using DMSO by a vapour induced phase separation (VIPS) mechanism. The porous electrospun PLA mats were shown to exhibit significantly increased oil absorption capacity compared with the non-porous fibre mats.
\end{abstract}

Keywords: electrospinning; porosity; poly(lactic acid); PLA; mechanisms; 


\section{Introduction}

Electrospinning is a versatile method of producing polymer fibres ranging from micron to nanoscale [1-3]. During electrospinning, polymer solutions can be drawn into one or multiple fibre jets under electrostatic forces, followed by a whipping motion [1]. The electrospun fibres are obtained after ultimate removal of the solvent(s) and have a large surface area to volume ratio.

By controlling processing parameters (e.g. applied voltage, flow rate and needle-to-collector distance), environmental parameters (e.g. temperature, humidity) and careful choice of polymersolvent systems, the resultant fibres may display unique surface and/or internal features, such as nano-pores, wrinkles and porous or hollow interiors. The porous features can further enhance the surface area to volume ratio and increase the functionality of the fibres.

Applications of porous electrospun fibres can range from sorbent materials for oil spill clean-up [4] to moisture wicking materials for sportwear [5]. Biomedical applications of these materials include scaffolds for tissue engineering [6-7] and carriers for drug delivery [8]. In tissue engineering, the porous fibres can mimic the native extracellular matrix (ECM) and the surface pores facilitate cell attachment, which is important for the restoration and regeneration of damaged tissue and organs [9]. In drug delivery, porosity of electrospun fibres may increase drug loading and efficacy.

Mechanisms to explain pore generation in polymer membranes (solvent cast or electrospun) are based on breath figures [10-12] and/or phase separation [13-29]. The breath figures method usually involves a hydrophobic polymer dissolved in a volatile solvent that is immiscible with water. During either casting or electrospinning of a polymer solution in a humid environment (normally with relative humidity above 50\%) evaporative cooling of the solvent can cause the water molecules from the surrounding air to condense on the polymer film surface. In this case, the water droplets act as hard spheres, leaving behind circular imprints and finally forming circular pores after evaporation.

Phase separation methods [30] can be categorised as thermally induced phase separation (TIPS), non-solvent induced phase separation (NIPS) and vapour induced phase separation (VIPS). Thermally induced phase separation (TIPS) involves the evaporation of a volatile solvent followed by a dramatic decrease in temperature, for example, by immersing the fibres in liquid nitrogen [17]. As a result, the homogeneous polymer solution becomes phase separated and forms a polymer-rich phase and a solvent-rich phase. Finally, a porous structure can be obtained after solvent evaporation is completed. However, this method is energy inefficient, which would be undesirable for mass production. In comparison, incorporation of a poor or nonsolvent can also induce phase separation and lead to porosity, which is a simple and energy efficient method, known as non-solvent induced phase separation (NIPS) [19-22]. In addition, porosity can also be induced by electrospinning a polymer in a water-miscible solvent with a high boiling point (e.g. dimethylformamide (DMF)) in a humid environment. In this case the mechanism is vapour induced phase separation (VIPS) [13,23-27]. Because water vapour is highly miscible with the solvent, water molecules readily penetrate into the fibre jets, leading to phase separation and a highly porous structure afterwards. However, to date, this method is only reported for production of highly porous PS and PMMA fibres, which has limited application in tissue engineering and drug delivery. 
Other methods, such as immersing fibres in a water bath [28,29] or selective removal of one component from fibres of a polymer blend $[18,21]$ are also available. However, these methods are more complicated because they require post treatment procedures.

Polylactic acid (PLA) is one of the most widely used aliphatic polyesters in tissue engineering and drug delivery applications, due to its biodegradability and excellent biocompatibility. However, one disadvantage of PLA is a lack of cell recognition sites, which is an important concern regarding tissue engineering. To improve its biomedical performance, modifications such as incorporation of additives or increasing surface area and surface roughness are necessary [31,32].

Some researchers have investigated electrospinning porous PLA fibres with a volatile solvent. In early research in 2001, Bognitzki and co-workers [33] first reported porous PLA fibres with pores on the fibre surface when electrospinning from dichloromethane (DCM), a volatile solvent. In comparison, Tan et al [34] did not report porosity in a PLA-DCM system. However, Casasola and co-workers [35] found porosity on the fibre surface when using both DCM and chloroform $(\mathrm{CHL})$ as single solvents. However, when using acetone, another volatile solvent, there were no pores. Similar results were also reported by Li and co-workers [36]. As a result, although some researchers have reported porous and nonporous PLA fibres, the exact mechanism whereby a volatile solvent can induce surface porosity is not well studied.

A combination of solvent and non-solvent (or poor solvent) has also been used to induce porosity in PLA fibres. When studying a ternary system composed of PLA/DCM/DMF, Natarajan and co-workers [37] found that the addition of DMF (10 \% v/v) resulted in surface porosity. Similar systems have been used to produce porous PLA fibres by Li et al [16]. Qi et al [20] reported a porous structure by using 1-butanol $(\mathrm{BuOH})$ as non-solvent to induce porosity on crystalline PLA fibres. However, the resultant PLA fibres lacked well-defined pores and uniform structures. In a recent paper, Rezabeigi et al [38] produced porous, micron-sized fibres of PLA by electrospinning PLA-DCM-hexane systems.

The aim of this study is to investigate the formation of porous electrospun fibres of PLA using a combination of solvents and non-solvents with differences in volatility and water miscibility. In this way, it is possible to obtain not only surface porosity with well-defined pores, but also highly porous structures with internal porosity or structures with both surface and internal porosity. Depending on the solvent selection, with relative humidity around $55 \%$, a variety of porous structures can be produced by different mechanisms: by 'breath figures', non-solvent induced phase separation (NIPS) or vapour induced phase separation (VIPS). For the first time, we report the use of Dimethyl sulfoxide (DMSO) as a single solvent to induce a highly porous structure in PLA fibres in a humid environment through the VIPS mechanism. In addition, we report a unique scalloped structure with regular shallow pores on the fibre surface. By controlling surface and internal morphologies, porous PLA fibres can be produced that may have the potential for improved performance in tissue engineering, wound dressings and drug delivery applications.

\section{Experimental}

\subsection{Materials}


Polylactic acid (PLA) pellets (Ingeo ${ }^{\text {TM }}$ 4060D) were supplied by Natureworks LLC (Minnetonka, USA). PLA 4060D is an amorphous polymer with an average D-lactide content of $12 \mathrm{wt}$. \% and a glass transition temperature $(\mathrm{Tg})$ of $55-60^{\circ} \mathrm{C}$. The weight average molecular weight $(\mathrm{Mw})$ of PLA 4060D as determined by gel permeation chromatography (GPC) was found to be 89,000 $\mathrm{g} / \mathrm{mol}$. The density of PLA 4060D at $25{ }^{\circ} \mathrm{C}$ is $1.24 \mathrm{~g} / \mathrm{cm}^{3}$. Prior to dissolution, PLA pellets were pre-dried in oven at $50{ }^{\circ} \mathrm{C}$ for $24 \mathrm{~h}$ to remove residual moisture.

Acetone (AC) (Chromasolv ${ }^{\circledR}$, for HPLC, $\geq 99.8 \%$ ) with an average molecular weight of 58.08 $\mathrm{g} / \mathrm{mol}$, chloroform (CHL) (CHROMASOLV ${ }^{\circledR}$, for HPLC, $\geq 99.8 \%$, amylene stabilized) with an average molecular weight of $119.38 \mathrm{~g} / \mathrm{mol}$ and dimethyl sulfoxide (DMSO) (CHROMASOLV ${ }^{\circledR}$ Plus, for HPLC, $\geq 99.7 \%$ ) were all purchased from Sigma-Aldrich Company Ltd (Dorset, UK). Ethanol (EtOH) with an absolute purity of $99.8+\%$ (certified AR for analysis) was purchased from Fisher Scientific (Loughborough, UK). All the solvents were used as received without further treatment.

Table 1 shows some properties of the selected solvents. Comparing the boiling points, DMSO can be regarded as a high boiling point liquid in comparison with the other three solvents.

Dielectric constant $(\varepsilon)$ is an important property because it is related to the polarity of the solvent. $\mathrm{CHL}$, with comparatively low dielectric constant, has low polarity, whereas DMSO is highly polar. Solvents with higher polarity have higher charge carrying ability and enhance the stability of the jet. Previous studies have shown that the dielectric constant of the solvent has significant influence on both fibre diameter [39] and jet stability [40]. AC and CHL were chosen as good solvents to dissolve PLA due to their Hansen solubility parameters ( $\left.\delta_{\text {total }}\right)$ being close to that of PLA (which is $\left.21.2(\mathrm{MPa})^{1 / 2}\right)$ [41]. EtOH and DMSO were chosen as non-solvent and poor solvent for PLA, respectively: their solubility parameters are significantly different from that of PLA. The hydrogen bonding index $\left(\gamma_{c}\right)$ reflects the miscibility of the solvent with water: the higher the value the more miscible is the solvent with water.

Table 1 Properties of solvents used in this study [42] (Dielectric constant, $\varepsilon$; Hansen solubility parameter, $\delta_{\text {total; }}$ hydrogen bonding index, $\mathrm{Yc}_{\mathrm{c}}$.

\begin{tabular}{|c|c|c|c|c|c|}
\hline Solvent & $\begin{array}{l}\text { Boiling Point } \\
\left({ }^{\circ} \mathrm{C}\right)\end{array}$ & $\boldsymbol{\varepsilon}$ & $\begin{array}{l}\delta_{\text {total }} \\
\left(\mathrm{MPa}^{1 / 2}\right)\end{array}$ & $Y_{c}$ & Structure \\
\hline $\begin{array}{l}\text { Acetone } \\
\text { (AC) }\end{array}$ & 56 & 20.6 & 19.7 & 9.7 & \\
\hline $\begin{array}{l}\text { Chloroform } \\
(\mathrm{CHL})\end{array}$ & 61 & 4.8 & 18.7 & 1.5 & $\mathrm{CHCl}_{3}$ \\
\hline $\begin{array}{l}\text { Ethanol } \\
(\mathrm{EtOH})\end{array}$ & 78 & 22.4 & 26.1 & 18.7 & $\mathrm{CH}_{3} \mathrm{CH}_{2} \mathrm{OH}$ \\
\hline $\begin{array}{l}\text { Dimethyl } \\
\text { Sulphoxide } \\
\text { (DMSO) }\end{array}$ & 189 & 46.6 & 26.7 & 7.7 & $\mathrm{H}_{3} \mathrm{C}$ \\
\hline
\end{tabular}




\subsection{Preparation of Spinning Solutions}

For the PLA solutions, a concentration of $15 \% \mathrm{w} / \mathrm{v}$ was chosen because at this concentration Casasola and co-workers [35] found that smooth and bead-free fibres could be electrospun. Homogeneous solutions were initially prepared by dissolving $3 \mathrm{~g}$ of PLA pellets in $20 \mathrm{ml}$ of either $\mathrm{AC}$ or $\mathrm{CHL}$ through magnetic stirring at room temperature $\left(22^{\circ} \mathrm{C}\right) . \mathrm{CHL}$ was mixed with either EtOH or DMSO in various ratios of good solvent/poor solvent: 95/5, 90/10, 80/20, 70/30 \%v/v and solutions with $15 \%$ w/v were prepared. Finally, for preparation of PLA in DMSO (poor solvent at room temperature), although pure DMSO at room temperature was unable to fully dissolve PLA, at elevated temperature of $80^{\circ} \mathrm{C}$, a homogeneous solution was formed. The detailed formulations are shown in Table 2.

Table 2 Formulations used in this study.

\begin{tabular}{|l|c|c|c|c|c|c|c|}
\hline $\begin{array}{l}\text { Solvent } \\
\text { system }\end{array}$ & $\begin{array}{c}\text { Mixing } \\
\text { Ratio } \\
(\% \mathrm{v} / \mathrm{v})\end{array}$ & $\begin{array}{c}\text { PLA } \\
\text { Concentration } \\
(\mathrm{w} / \mathrm{v})\end{array}$ & $\begin{array}{c}\text { PLA } \\
(\mathrm{g})\end{array}$ & $\begin{array}{c}\mathrm{AC} \\
(\mathrm{ml})\end{array}$ & $\begin{array}{c}\mathrm{CHL} \\
(\mathrm{ml})\end{array}$ & $\begin{array}{c}\text { EtOH } \\
(\mathrm{ml})\end{array}$ & $\begin{array}{c}\text { DMSO } \\
(\mathrm{ml})\end{array}$ \\
\hline $\mathrm{AC}$ & Pure & $15 \%$ & 3 & 20 & - & - & - \\
\hline $\mathrm{CHL}$ & pure & $15 \%$ & 3 & - & 20 & - & - \\
\hline \multirow{3}{*}{ CHL/EtOH } & $95 / 5$ & $15 \%$ & 3 & - & 19 & 1 & - \\
\cline { 2 - 9 } & $90 / 10$ & $15 \%$ & 3 & - & 18 & 2 & - \\
\cline { 2 - 9 } & $80 / 20$ & $15 \%$ & 3 & - & 16 & 4 & - \\
\cline { 2 - 9 } & $70 / 30$ & $15 \%$ & 3 & - & 14 & 6 & - \\
\hline \multirow{3}{*}{ CHL/DMSO } & $95 / 5$ & $15 \%$ & 3 & - & 19 & - & 1 \\
\cline { 2 - 8 } & $90 / 10$ & $15 \%$ & 3 & - & 18 & - & 2 \\
\cline { 2 - 8 } & $80 / 20$ & $15 \%$ & 3 & - & 16 & - & 4 \\
\cline { 2 - 8 } & $70 / 30$ & $15 \%$ & 3 & - & 14 & - & 6 \\
\hline DMSO & Pure & $15 \%$ & 3 & - & - & - & 20 \\
\hline
\end{tabular}

\subsection{Electrospinning Process}

A vertical Spraybase ${ }^{\circledR}$ (Dublin, Ireland) electrospinning equipment was used (see supporting information Fig. S1). The polymer solution was placed in a 3-ml plastic syringe (Luer lock syringe, Sigma Aldrich) that was connected to the needle by PTFE capillary tubing. A pump system (PHD ULTRA ${ }^{\mathrm{TM}}$, Harvard Apparatus) was used to feed a constant solution $(1.0 \mathrm{ml} / \mathrm{h})$ through the needle. A high voltage power supply was used to generate an electric field of $8.5 \mathrm{kV}$ between the needle and the collector, which was a rectangular copper plate covered with aluminium foil and located $10 \mathrm{~cm}$ away from the needle tip. During the electrospinning process, a Taylor cone can be observed. Electrospinning experiments were performed at room temperature $\left(\sim 22{ }^{\circ} \mathrm{C}\right)$ with a relative humidity $(\mathrm{RH})$ of $\sim 55 \%$. The fibre mats collected were kept 
in a fume hood for over $24 \mathrm{~h}$ to fully remove residual solvent and non-solvent. Each formulation was made up and electrospun three times.

\subsection{Characterisation of Morphology}

\subsubsection{Scanning Electron Microscopy}

The morphologies of the PLA fibres from different solvent systems were observed in detail by using a JSM-7100F Field Emission Scanning Electron Microscope (FE-SEM). The samples were coated with gold and then observed in the FE-SEM with low accelerating voltages of 2 5 $\mathrm{KV}$, in order not to damage the surface morphologies of the samples.

\subsubsection{Image Analysis}

For analysing the SEM images, Image $\mathrm{J}$ software was used to measure the fibre diameters and OriginPro 9.0 was used to plot fibre diameter distributions.

\subsection{Oil Sorption Measurements}

Some simple oil sorption measurements were carried out at room temperature using the following procedure. $20 \mathrm{~g}$ of mineral oil was placed in a glass jar. The dried electrospun fibre mats were immersed in the oil for $30 \mathrm{~s}$. Then the wet fibre mats were removed using tweezers and drained for another $30 \mathrm{~s}$. The oil sorption capacities of the fibre mats were calculated from equation (1):

$$
\mathrm{Q}=\frac{M t-M 0}{M 0} \text {. }
$$

where $Q$ is the oil sorption capacity $(\mathrm{g} / \mathrm{g}), \mathrm{Mt}_{\mathrm{t}}$ is the mass of the wet fibre mats after oil sorption for $30 \mathrm{~s}, \mathrm{M}_{0}$ is the mass of the fibre mats before sorption. The measurement was carried out three times and the mean and standard deviation were calculated.

\subsection{Contact angle measurements}

Contact angle measurements of deionized water $(0.25 \mu \mathrm{L})$ on the surface of non-porous and porous PLA fibre mats were performed using a DataPhysics OCA 20 instrument (Filderstadt, Germany). The contact angle of deionized water $(0.25 \mu \mathrm{L})$ on melt processed PLA sheet was also measured as a reference. Ten measurements were performed on different positions on the samples.

\section{Results and Discussion}

\subsection{Breath Figures Mechanism for Pore Formation}

The choice of solvent is a key factor that influences the properties of electrospun fibres. Acetone $(\mathrm{AC})$ and chloroform $(\mathrm{CHL})$ are commonly used solvents to dissolve PLA. They are both good solvents for PLA and both volatile (Table 1). However, the morphologies of the electrospun fibres are very different.

As shown in Fig. 1, the PLA fibres from electrospinning AC solution have a smooth surface and uniform fibres of $585 \pm 125 \mathrm{~nm}$ in diameter. These results are similar to those reported by Casasola et al [35]. 

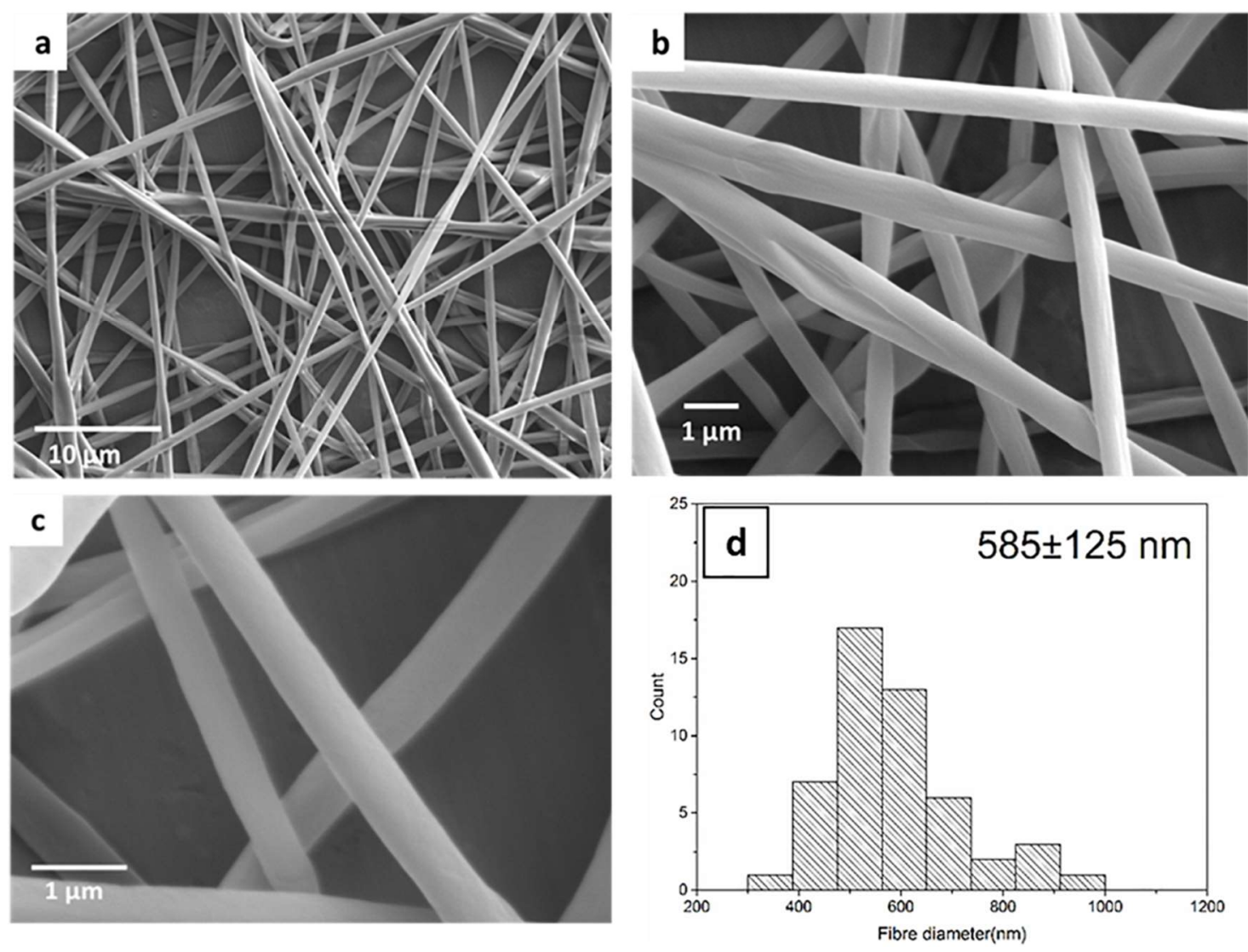

Fig. 1 SEM images of electrospun PLA fibres from AC

In comparison, the electrospun PLA fibres from CHL solution show a rough, uneven surface and a broad variation of fibre diameters. There are seen to be single fibres ranging from a few hundred nanometres to about 10 microns in diameter in the same fibre (Fig. 2a Type 1). There are also some thin, uniform fibres of only a few hundred nanometres (Fig. 2a Type 2). The thin fibres have non-wrinkled surfaces (Fig. 2c), but thick fibres showed irregularly wrinkled surfaces (Fig. 2b). In addition, some bead-like structures tend to occur. These results are due to the very low dielectric constant of CHL (4.8) compared with that of AC (20.6). The low dielectric constant of $\mathrm{CHL}$ gives rise to low surface charge density during electrospinning and therefore gives rise to an unstable jet and very non-uniform fibres [43]. The diameter distribution is $3062 \pm 3200$

(Fig. 2d). It is also interesting to find that there are roughly circular pores ranging from 20 to 200 $\mathrm{nm}$ on the surface of both thin and thick fibres. 

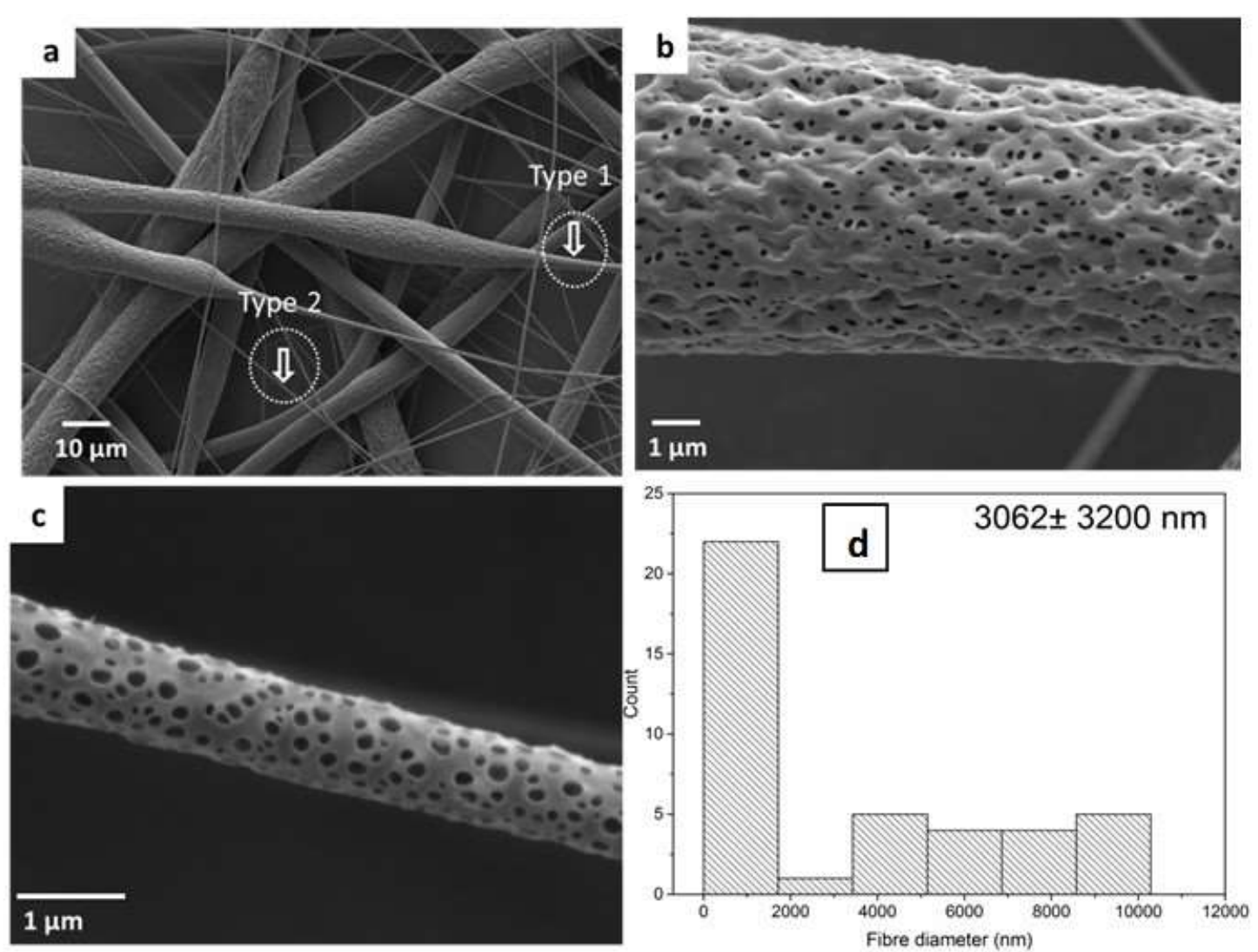

Fig. 2 SEM images of electrospun PLA fibres from CHL (a) at x2500 (b) magnified image of Type 1, (c) magnified image of Type 2, and (d) fibre diameter distribution.

As discussed earlier, there are a number of different mechanisms to explain pore formation. Vapour induced phase separation (VIPS), thermally induced phase separation (TIPS) and breath figures are the main mechanisms to explain the formation of porosity when electrospinning polymer from a single solvent system. Since $\mathrm{CHL}$ is a volatile solvent that is immiscible with water, the VIPS mechanism is not applicable in this case, because high boiling point and water miscibility are the key requirements for the VIPS mechanism. TIPS and breath figures both involve solvent evaporation and evaporative cooling; the difference is that for the TIPS mechanism, a dramatic temperature decrease is required to induce phase separation, which did not happen in this experiment. For the breath figures mechanism, a humid environment is needed - in this case, the porous fibres were electrospun from $\mathrm{CHL}$ at $55 \% \mathrm{RH}$. Due to the evaporative cooling of the solvent, water vapour condenses on the surface of the fibre jets to form droplets. Porosity can be formed when the droplets evaporate. For the breath figure induced porosity, generally only surface porosity is achieved.

In addition, the cross-sections of fibres confirm that only surface porosity was formed from CHL. The images can be found in supplementary information Fig.S2(a). As a result, it is concluded that the surface porosity for $\mathrm{CHL}$ is attributable to the breath figures mechanism. For completeness, the section through fibres electrospun from AC is included in Fig.S2(b): no porosity is found.

A schematic diagram of surface pore formation by the 'breath figures' mechanism is shown in Fig. 3. During the process of electrospinning PLA from CHL in a humid environment, volatile $\mathrm{CHL}$ solvent molecules evaporate, leading to a cooling effect that causes water vapour to condense on the surface of the fibre, forming water droplets. The condensed water droplets can 
stabilise and appear on the fibre surface due to the hydrophobicity of PLA and water immiscibility of CHL. After final evaporation of $\mathrm{CHL}$ and water, the water droplets leave behind imprints to form circular pores on the surface.

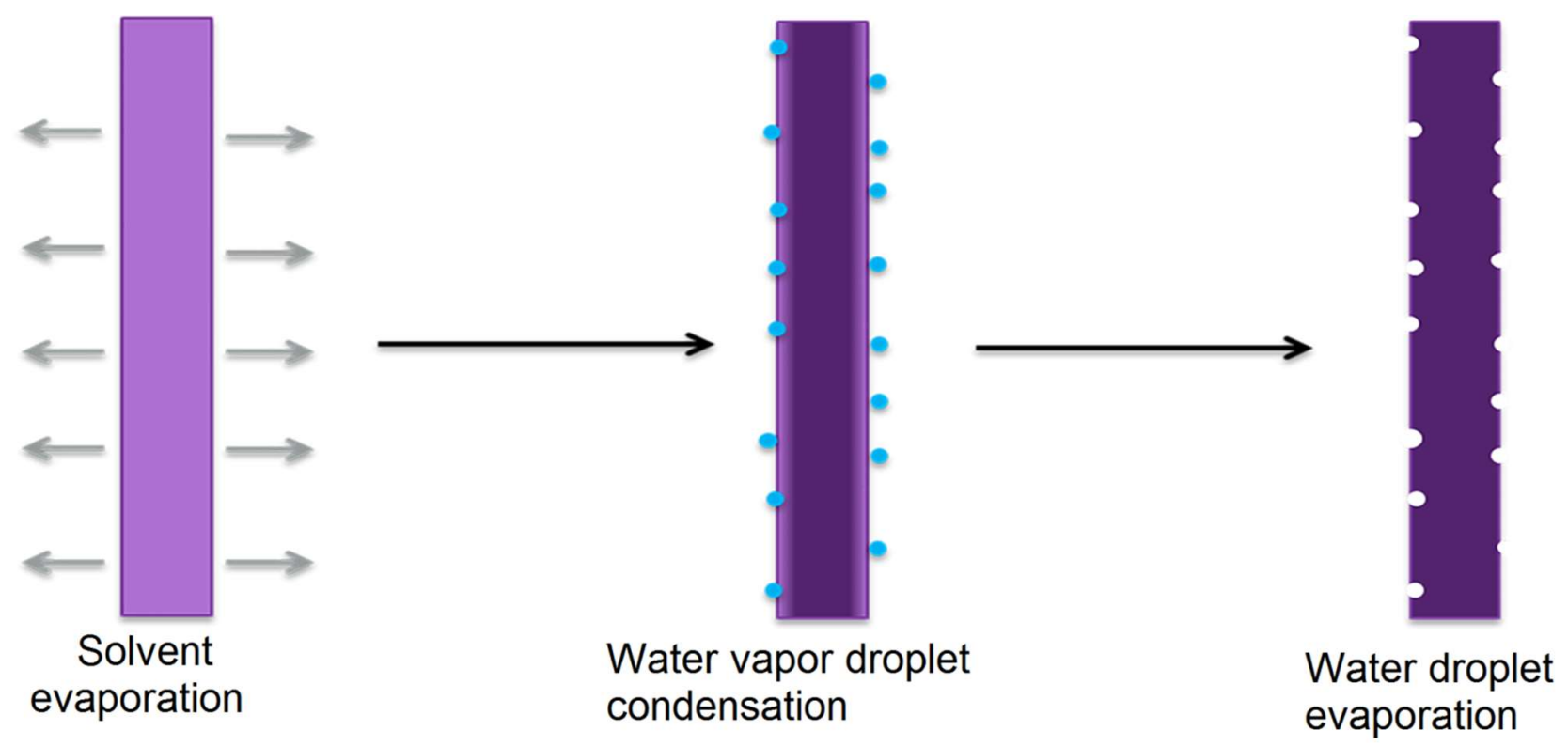

Fig. 3 Schematic diagram of surface pore formation induced by breath figures mechanism

\subsection{Non-solvent Induced Phase Separation (NIPS) Mechanism for Pore Formation}

Although the breath figures mechanism is a convenient method to induce surface porosity, the solvent required is generally volatile and water immiscible, such as benzene, DCM and CHL, which have low dielectric constants that can cause difficulty in continuous production of the fibres and give rise to a wide distribution of fibre diameters. To improve fibre uniformity, a nonsolvent (or poor solvent) can be introduced to give a polymer/solvent/non-solvent ternary system. The non-solvent should have a higher boiling point and higher dielectric constant than the solvent to facilitate fibre production and fibre uniformity as well as porosity (at a certain solvent/non-solvent ratio). In this study, a non-solvent, EtOH, and a poor solvent, DMSO, were used to form PLA/CHL/EtOH and PLA/CHL/DMSO ternary systems at different ratios.

\subsubsection{PLA/CHL/EtOH Ternary System}

Ethanol $(\mathrm{EtOH})$ is a volatile non-solvent for PLA. The boiling point of EtOH $\left(78^{\circ} \mathrm{C}\right)$ is slightly higher than that of $\mathrm{CHL}\left(61^{\circ} \mathrm{C}\right)$. $\mathrm{CHL} / \mathrm{EtOH}$ at different ratios $(95 / 5,90 / 10$ 80/20, 70/30 \%v/v) were used to electrospin PLA fibres. The SEM images and diameter distributions in Fig. 4 indicate that, with increasing ethanol content, the mean fibre diameter decreased from $3095 \mathrm{~nm}$ to $1490 \mathrm{~nm}$ with a greatly reduced standard deviation. The reason for the improved fibre uniformity is probably due to the increased dielectric constants of the solutions [40]. 

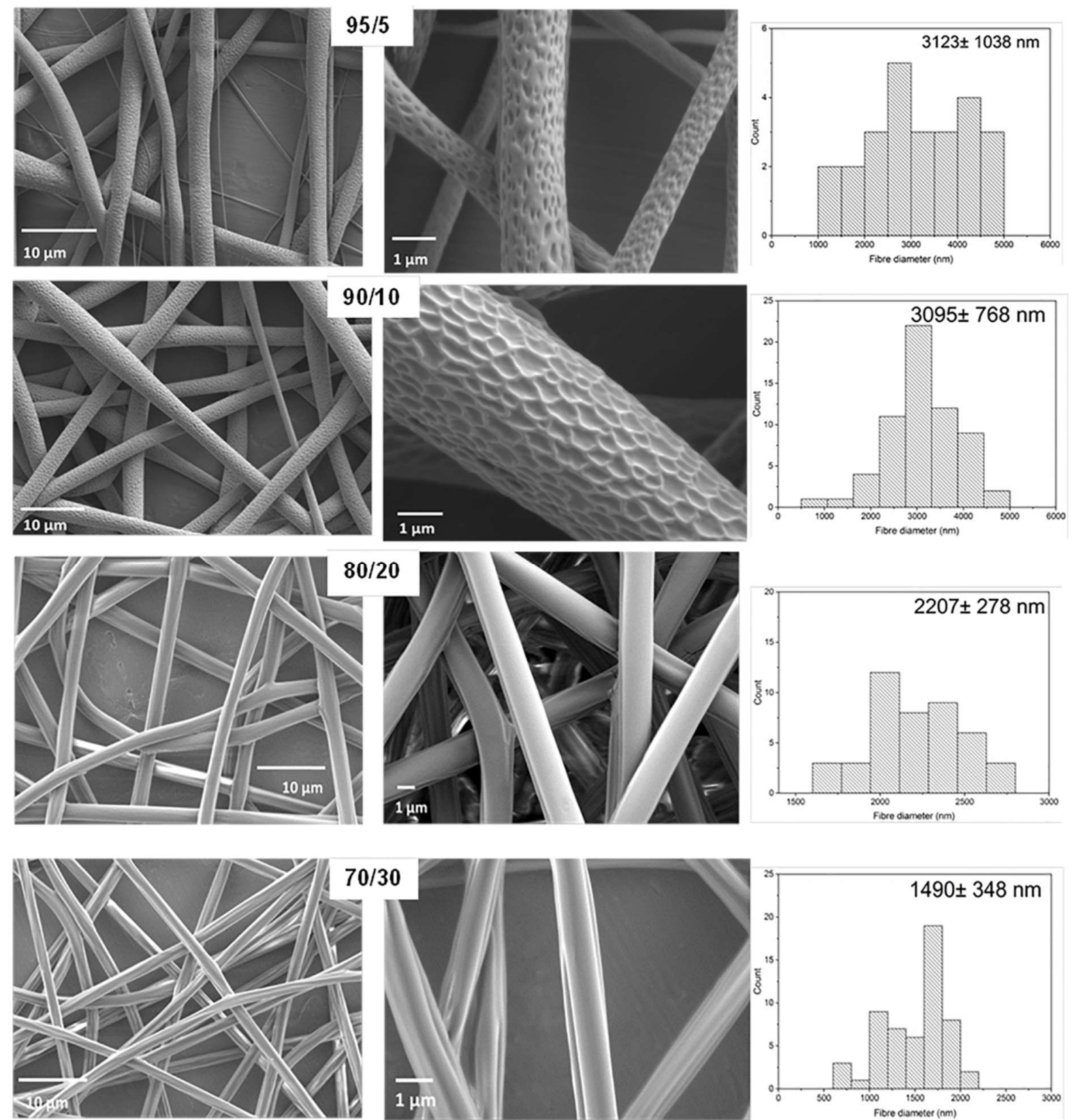

Fig. 4 SEM images of PLA fibres from $\mathrm{CHL} / \mathrm{EtOH}$ at different mixing ratios.

Surface porosity was induced using the $95 / 5 \mathrm{CHL} / \mathrm{EtOH}$ solution. This porosity appears similar to that produced with pure chloroform by the breath figures mechanism but the pores are elliptical and shallower. With the addition of $10 \% \mathrm{v} / \mathrm{v}$ of EtOH, the shallow pores have expanded, forming a scalloped surface consisting of shallow surface pores connected by ridges. To the best of our knowledge, this unique structure has not been reported before. With further increase in EtOH content, the surface porosity disappears to give a smooth surface with a few wrinkles. The morphological evolution of the fibres with increasing amount of EtOH can be described as follows: fibres with surface porosity $\rightarrow$ scalloped surface $\rightarrow$ smooth fibres with a few wrinkles.

To study the internal morphology of PLA/CHL/EtOH ternary systems, cross-sections of the electrospun fibres were examined. As shown in Fig. 5, it is seen that in all compositions, the electrospun fibres from PLA/CHL/EtOH ternary solution systems showed solid interiors. Note 
that stretching of the fibre surface occurs due to deformation of the soft fibres during cutting of the cross-section.
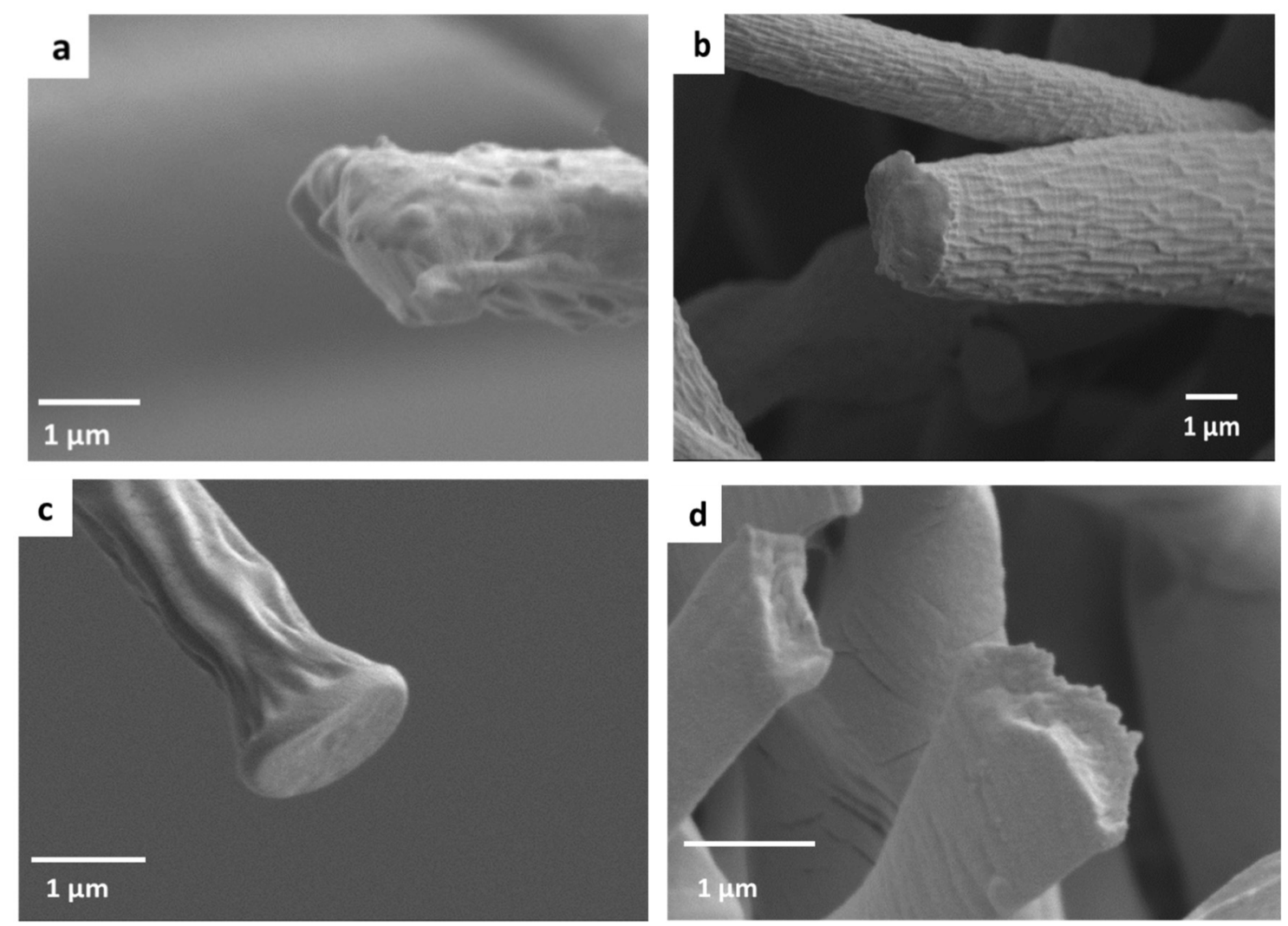

Fig. 5 SEM images of cross-sections of PLA fibres electrospun using CHL/EtOH with (a) 95/5 (b) $90 / 10$ (c) $80 / 20$ (d) $70 / 30 \%$ v/v.

Fig. 6 is a schematic diagram of the formation of surface porosity by the non-solvent induced phase separation (NIPS) mechanism. This diagram is particularly focussed on the scalloped surface structure formed by the 90/10 CHL/EtOH sample. Due to their difference in boiling point, $\mathrm{CHL}$ will evaporate more readily than $\mathrm{EtOH}$. Hence, the solvent evaporates more quickly than the non-solvent and there is a continuous reduction in the solvent/non-solvent ratio as electrospinning proceeds. This results in the single-phase homogeneous ternary system entering a two-phase heterogeneous region. Non-solvent droplets will form at the surface of the electrospun fibres due to phase separation.

As in the case of the breath figures mechanism discussed in section 3.1, during the process of electrospinning of PLA dissolved in a volatile solvent, such as CHL, if the process is carried out in a humid environment, then the evaporation of the solvent will cause a cooling effect that gives rise to condensation of water droplets on the surface of the fibres. However, water and EtOH are highly miscible and the droplets will spread over the surface of the fibres during electrospinning. On evaporation, the scalloped surface is formed. As the amount of ethanol is increased, the droplets spread to cover the surface and smooth fibres with some surface wrinkles are obtained. 


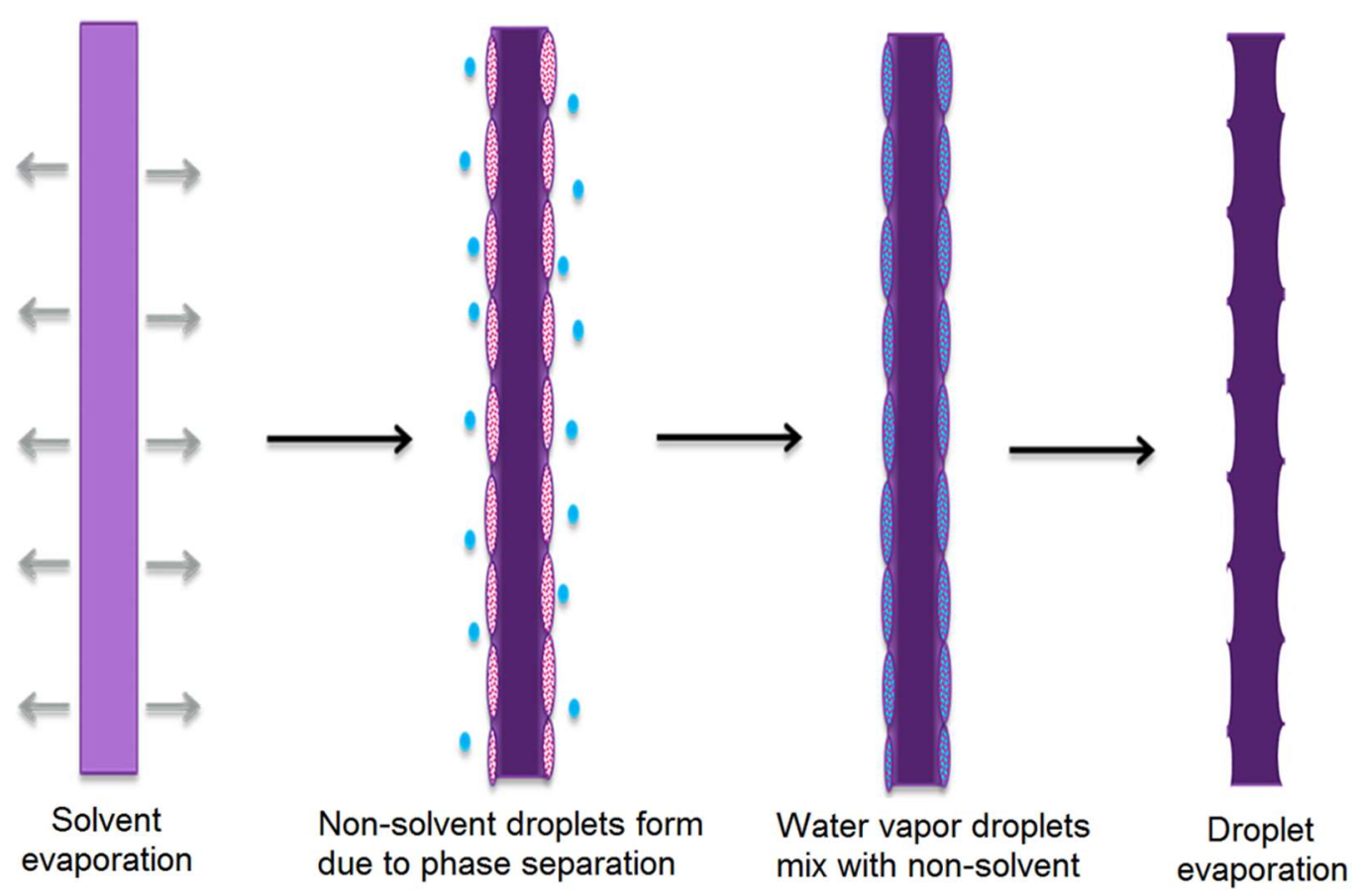

Fig. 6 Schematic diagram of non-solvent induced phase separation (NIPS) process, showing surface porosity.

\subsubsection{PLA/CHL/DMSO ternary system}

DMSO has a high boiling of $189^{\circ} \mathrm{C}$ and is a poor solvent for PLA. Sato et al [41] immersed films of PLA in DMSO and found that the PLA films did not dissolve, although a strong swelling effect was observed. Our preliminary work showed that $3 \mathrm{~g}$ of PLA pellets could not fully dissolve in 20 $\mathrm{ml}$ of DMSO solvent even after magnetic stirring for 48 hours at room temperature. This confirms that DMSO is a poor solvent for PLA at room temperature $\left(22^{\circ} \mathrm{C}\right)$.

Images of electrospun fibres of PLA from CHL/DMSO solutions at solvent ratios of 95/5, 90/10, $80 / 20$ and 70/30 v/v are shown in Fig 7 . The addition of DMSO helped produce bead-free fibres. Also, the fibre diameter distribution significantly improved, which is because addition of DMSO increased the dielectric constants of the solutions, leading to more uniform fibres. Addition of DMSO (from 5 to $30 \% \mathrm{v} / \mathrm{v}$ ) reduced the mean fibre diameter from $1630 \pm 766$ to $1220 \pm 268 \mathrm{~nm}$.

In terms of surface porosity, it was found that with addition of DMSO from 5 to $20 \% \mathrm{v} / \mathrm{v}$, there were a lot of elliptical pores on the fibre surfaces. With a further increase in DMSO (up to $30 \%$ $\mathrm{v} / \mathrm{v}$ ) the surface pores disappeared and, instead, wrinkled structures appeared. The morphological evolution of the fibres with increasing amount of DMSO can be described as follows: fibres with elliptical surface pores $\rightarrow$ non-porous fibres with wrinkles. A similar trend from porous to non-porous wrinkled fibres with increasing content of poor solvent was found by Katsogiannis and co-workers [19] when electrospinning PCL from CHL/DMSO, although no explanation was given for the transition from porous to wrinkled structures. 

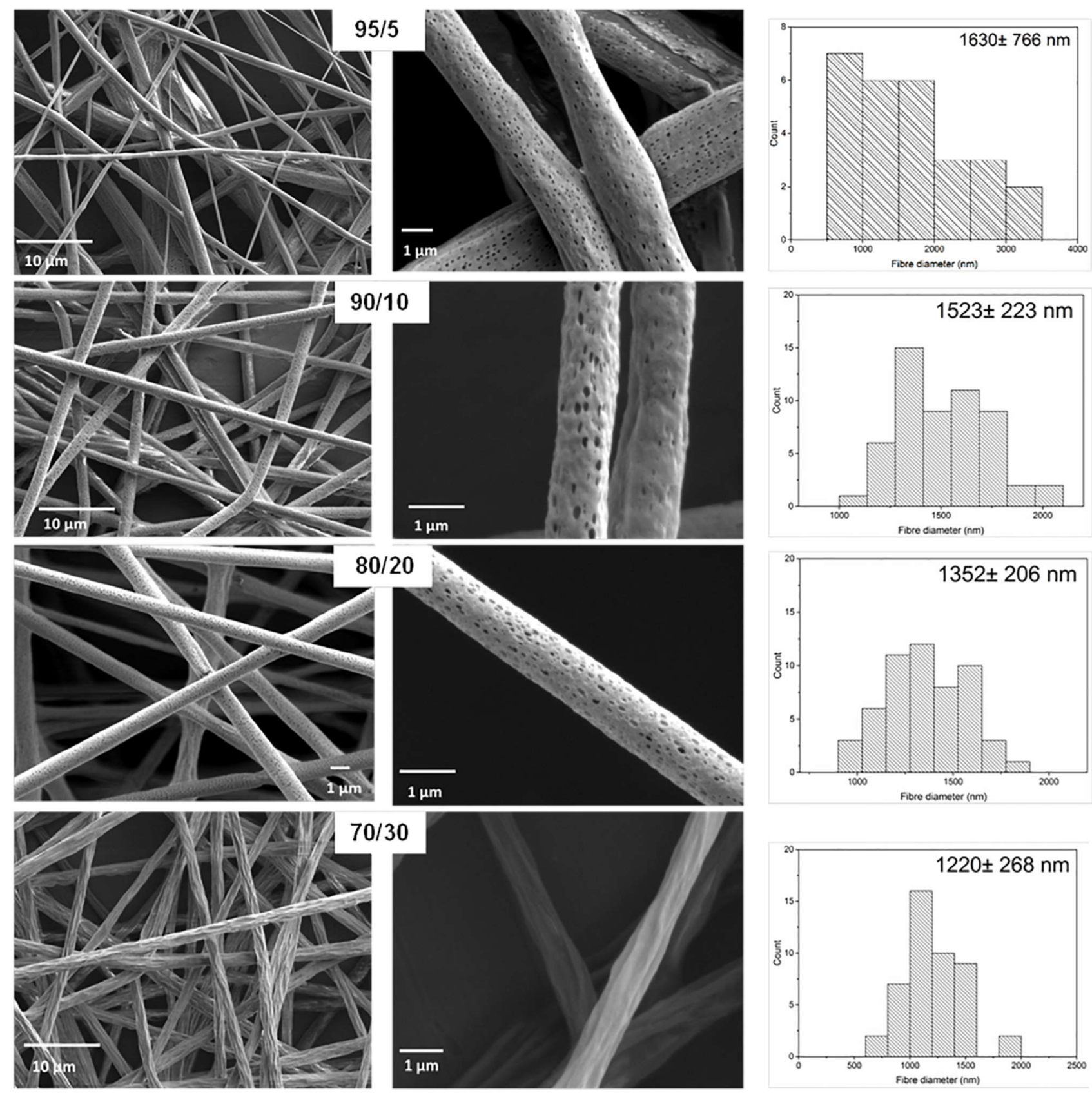

Fig. 7 SEM images of PLA fibers from CHL/DMSO at different mixing ratios in \%v/v.

Cross-sections through the fibres were examined to investigate their internal morphology. For the fibres electrospun with the addition of $5-20 \%$ DMSO, which were the fibres with surface porosity, it was found that they had solid interiors, as shown in Fig. 8 a-c. With the addition of $30 \% \mathrm{v} / \mathrm{v}$ of DMSO, where the fibres were found to have wrinkled surfaces, the fibres displayed internal porosity (Fig. 8 d) and there is seen to be a multi-channelled interior structure. 

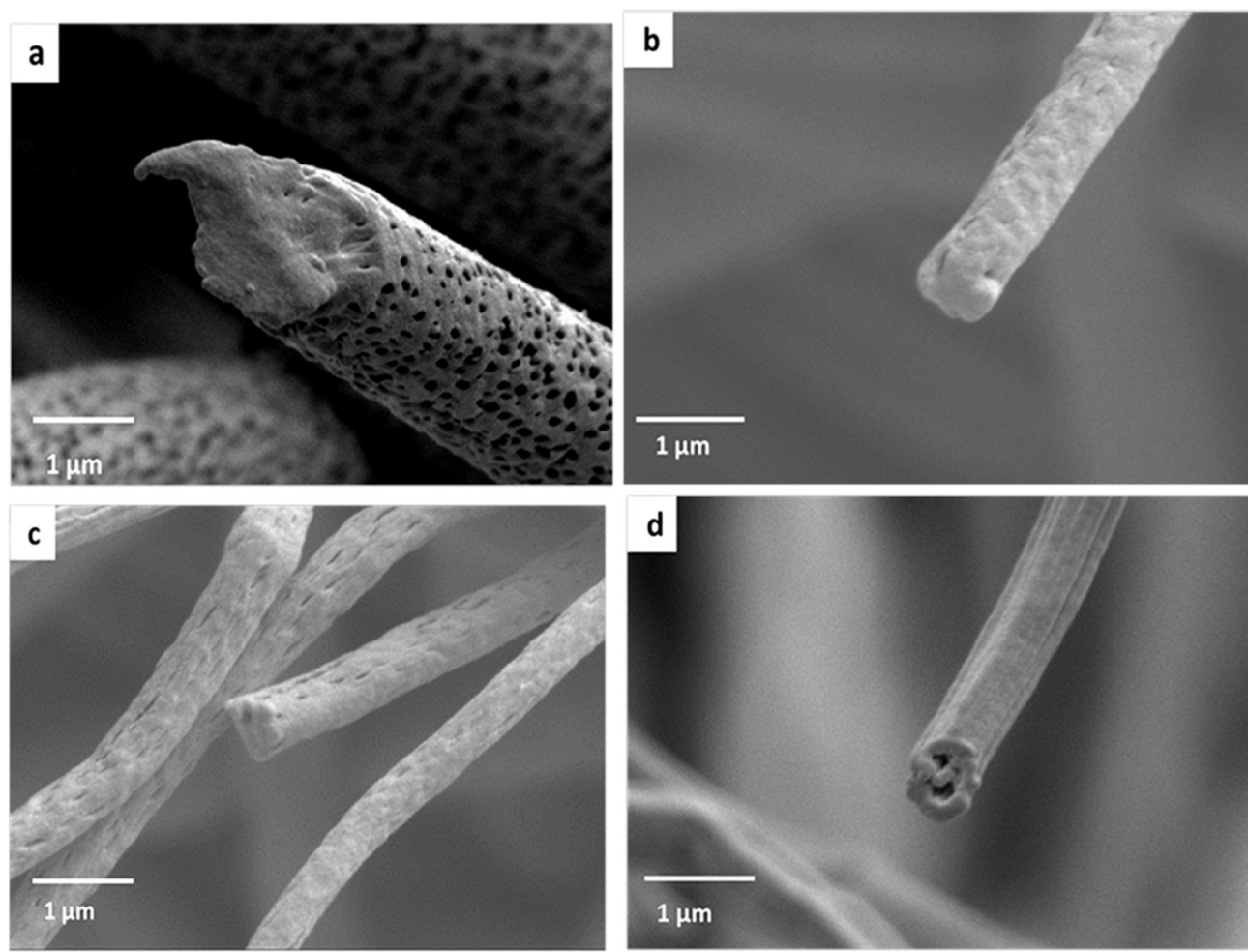

Fig. 8 SEM images of cross sections of PLA fibers from CHL/DMSO (a) 95/5, (b) 90/10, (c) $80 / 20$, (d) $70 / 30$ in $\% \mathrm{v} / \mathrm{v}$.

The fabrication of hollow electrospun fibres has been reported in a number of studies using a co-axial electrospinning setup [44]. In this case a co-axial spinneret is used to generate coreshell fibres and the core material is subsequently removed, leading to hollow structures. However, there are few studies on producing fibres with porous interiors using a single spinneret. Zhang et al [45] reported a porous structure when producing PLLA fibres from DCM/DMF $75 / 25 \% \mathrm{v} / \mathrm{v}$ but when using less DMF or using pure DCM as solvent, no porous structures were observed. There was no explanation of the mechanism inducing the internal porosity.

In our study, we found porous interiors when using $30 \% \mathrm{v} / \mathrm{v}$ of DMSO (shown in Fig. 8d) but no internal porosity occurred when using $\mathrm{EtOH}$. There is a large difference in volatility between DMSO and EtOH (boiling point: DMSO $189^{\circ} \mathrm{C}$, EtOH $78^{\circ} \mathrm{C}$ ). In PLA/CHL/EtOH systems, EtOH readily diffuses outwards and so $\mathrm{EtOH}$ is unlikely to remain inside the fibres. In contrast, for the $\mathrm{PLA} / \mathrm{CHL} / \mathrm{DMSO}$ systems, the volatility of DMSO is much lower and so DMSO tends to remain in the centre of the fibres. Fig. 9 is a schematic diagram of the formation of internal porosity by the non-solvent induced phase separation (NIPS) mechanism. During CHL evaporation, DMSO is mainly concentrated at the centre of the fibres and this can lead to phase separation with the polymer, forming non-solvent droplets. These droplets can undergo coalescence due to a relatively long drying time and form internal porosity when DMSO fully evaporates. It is worth mentioning that a sufficient amount of non-solvent (poor solvent) with high boiling point is necessary to ensure that phase separation occurs. Hence internal porosity was first detected when the DMSO content reached $30 \%$.

It may be argued that the internal porosity could be induced by vapour induced phase separation (VIPS) due to the addition of DMSO in the PLA/CHL/DMSO systems. A watermiscible non-solvent can absorb water vapour from the atmosphere, which can cause phase 
separation. Indeed, as mentioned earlier, the droplets at the fibre surface may absorb some water vapour causing a wrinkled surface effect. In fact, the mass transfer in the VIPS mechanism is very slow [46]. In our case, due to the high volatility of $\mathrm{CHL}$, the polymer jet tends to form a skin on the surface very rapidly [47], and the vicinity of the fibre surface will be saturated with $\mathrm{CHL}$ vapour. As a result, it is unlikely that water vapour penetrates into the fibre interiors and causes phase separation, suggesting that the internal porosity is induced by a NIPS mechanism.

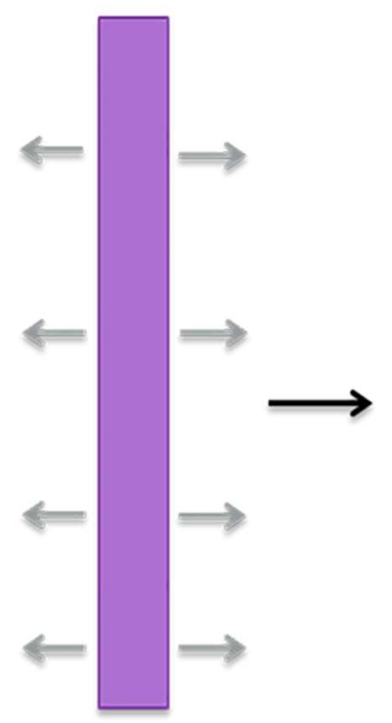

Solvent evaporation

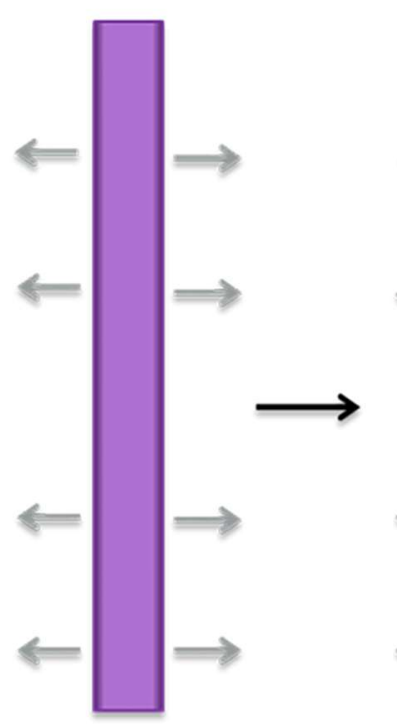

Non-solvent concentrated in center

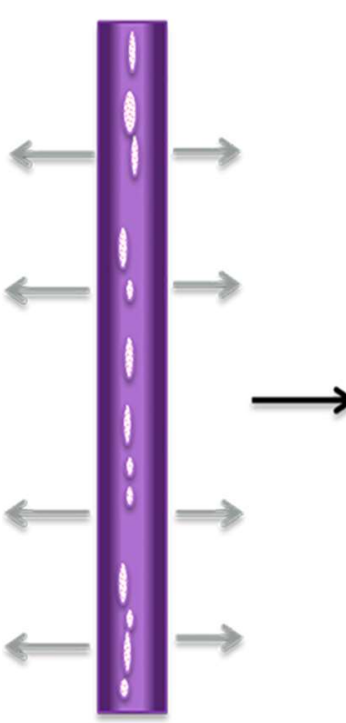

Non-solvent droplets form due to phase separation

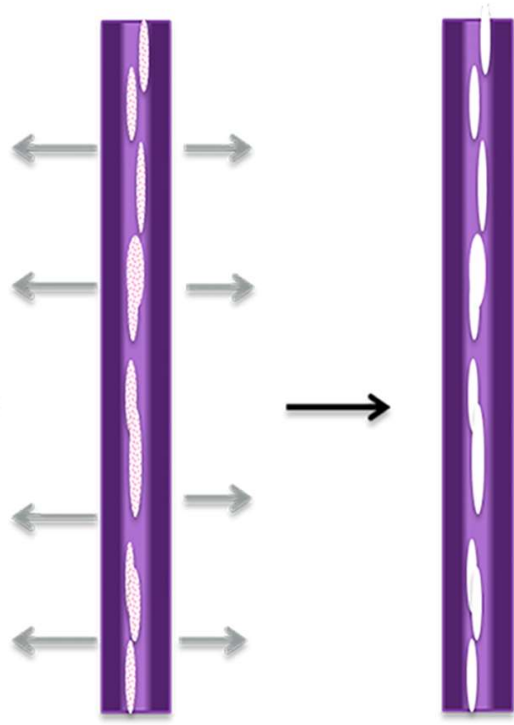

Droplet coalescence occurs
Internal porosity when evaporation completes

Fig. 9 Schematic diagram of internal porosity induced by non-solvent induced phase separation (NIPS).

\subsection{Vapour induced phase separation (VIPS)}

The SEM images in Fig. 10 show that by using DMSO as a single solvent, uniform fibres can be produced with average fibre diameter $1129 \pm 261 \mathrm{~nm}$. It is interesting to note that not only surface porosity, but also internal porosity is found (more images are shown in supplementary information Fig. S3). 

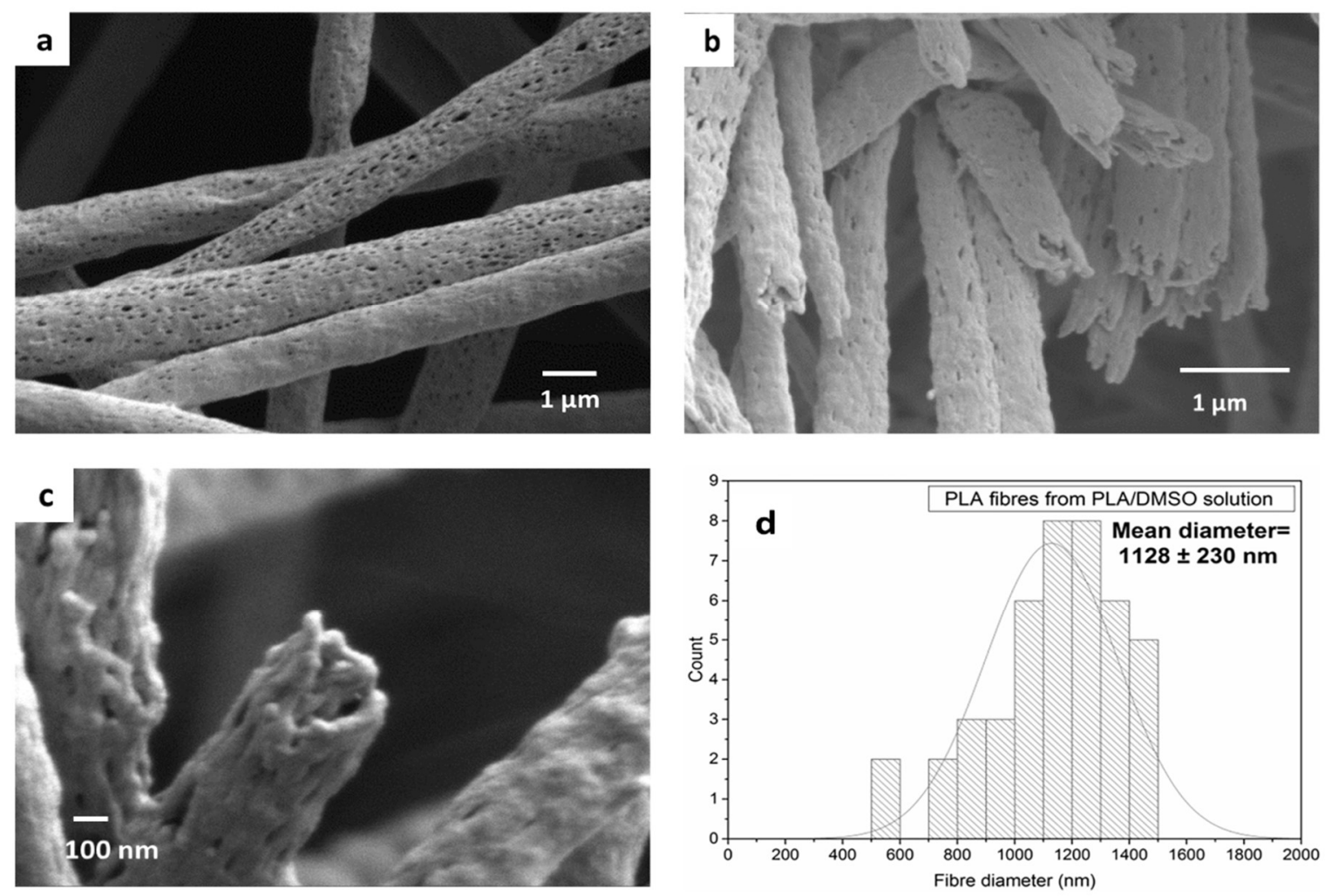

Fig. 10 SEM images of highly porous PLA fibers with both surface and internal porosity induced by vapor induced phase separation (VIPS) in a humid environment ( 55\%): (a-b) surface, (c) internal porosity, and (d) fibre diameter distribution.

To account for this highly porous structure, the vapour induced phase separation (VIPS) mechanism is the most probable explanation because both the 'breath figures' and TIPS mechanisms involve a volatile solvent, and the NIPS mechanism involves a combination of solvent and non-solvent in the spinning solutions.

Other studies have shown that a humid environment and selection of a water miscible solvent with a high boiling point are necessary to produce porous membranes $[48,49]$ and porous fibre mats [13,24-26] induced by VIPS. DMSO is a water-miscible solvent with a high boiling point of $189^{\circ} \mathrm{C}$. Although it is a poor solvent for PLA, it was possible to dissolve PLA in DMSO at $80^{\circ} \mathrm{C}$. On being cooled to room temperature, the solution was still homogeneous and suitable for electrospinning. The process was carried out at a humidity of $\sim 55 \%$. 


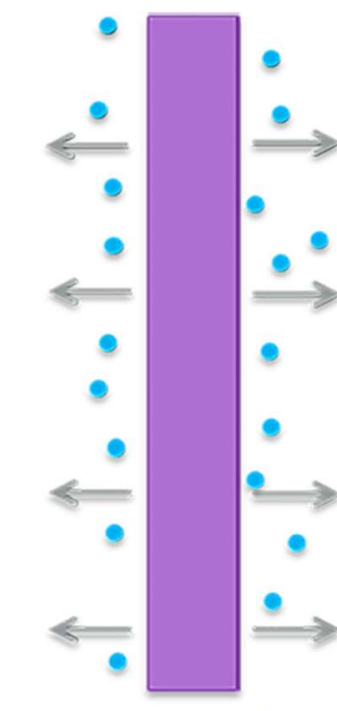

Solvent slow evaporation and water penetration

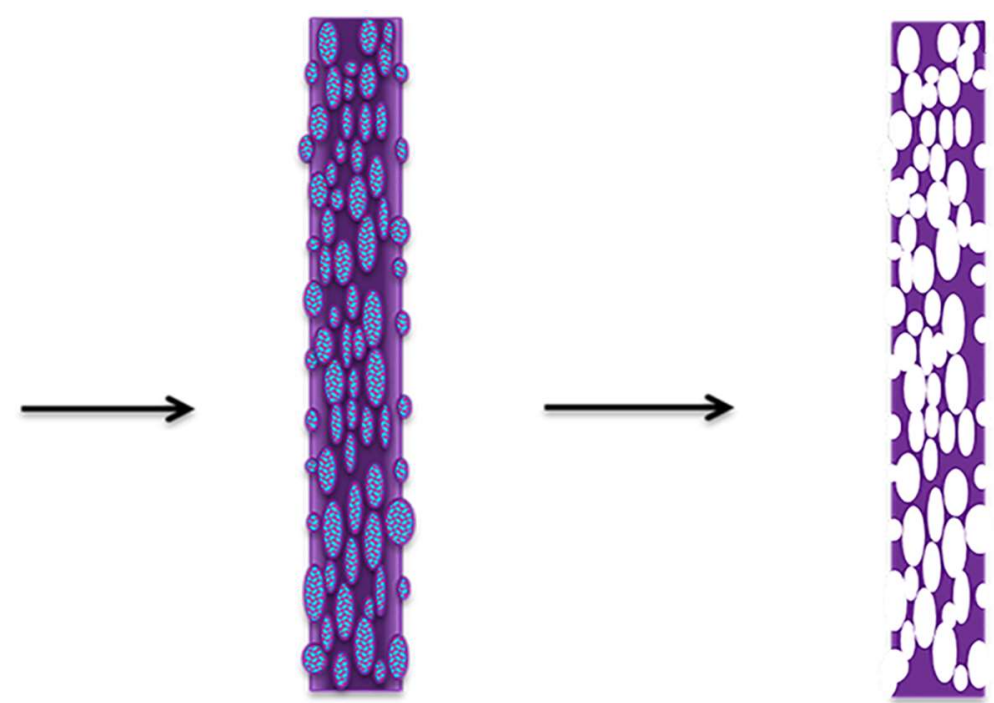

Phase separation occurs due to solvent mixing with water
Highly porous structure forms when evaporation completes

Fig. 11 Schematic diagram of porosity induced by a vapor induced phase separation (VIPS) mechanism.

Fig. 11 is a schematic diagram of the formation of highly porous electrospun fibres by the vapour induced phase separation (VIPS) mechanism. In a humid environment, water vapour is readily attracted to the surface of the fibre jets since water and DMSO are highly miscible. With no other solvent present and limited evapouration of DMSO, water vapour can penetrate into the core of the fibre jets. The presence of water vapour acts as a non-solvent for PLA, inducing phase separation and causing the highly porous structures after water and DMSO molecules fully evaporate. Because of the low volatility of DMSO, there is sufficient time for water vapour to penetrate and induce internal porosity before complete drying.

There are some papers investigating use of the VIPS mechanism to produce highly porous electrospun polystyrene (PS) $[13,24,25]$ and poly(methyl methacrylate) (PMMA) [26] fibres from $\mathrm{N}, \mathrm{N}$-dimethyl formamide (DMF). To the best of our knowledge, this is the first time that highly porous PLA fibres have been produced by the VIPS mechanism using DMSO.

Lastly, it should be noted that by using DMSO, a continuous production of uniform fibres can be achieved. This is much better than using volatile solvents, such as acetone and chloroform, where rapid solvent evaporation leads to polymer solidification that can block the needle and slow fibre production.

\subsection{Oil Sorption Tests}

\subsubsection{Sorption capacity test with mineral oil}

The mechanisms of oil sorption for porous fibre mats can be adsorption, capillary action or a combination of these [4]. Oil sorption capacities of the fibre mats can be influenced by fibre properties [4, 50], oil types [50] and sorption time [27]. Fig. 12 compares the oil sorption capacities of electrospun PLA fibre mats with different morphologies using mineral oil as the medium and fixing the sorption time at 30 s. The non-porous PLA fibres electrospun from AC 
showed the lowest oil sorption capacity of $25 \pm 4.1 \mathrm{~g} / \mathrm{g}$. The PLA fibre mats electrospun using the solvent combination CHL/DMSO $80 / 20 \% \mathrm{v} / \mathrm{v}$ showed increased sorption capacity (60 $\pm 4 \mathrm{~g} / \mathrm{g}$ ) attributable to the presence of surface porosity. Mats electrospun from CHL/DMSO 70/30 \%v/v showed a further increase in the oil sorption capacity $(82.6 \pm 5.6 \mathrm{~g} / \mathrm{g})$, which is likely to be due to the interior porosity causing a capillary action. The highest sorption capacity was achieved with PLA fibre mats electrospun from DMSO $(104.7 \pm 5.4 \mathrm{~g} / \mathrm{g})$ again attributable to the highly porous structure with both surface and internal porosity, leading to a combination of adsorption and capillary action.

It has been demonstrated that both finer fibres and porosity can enhance oil sorption capacities of electrospun fibre mats [50]. In our results, the non-porous PLA fibres electrospun from AC showed the lowest oil sorption but the diameter of these fibres was about half that of the various porous fibres. This indicates that porosity is playing a more important role in oil sorption than fibre diameter.

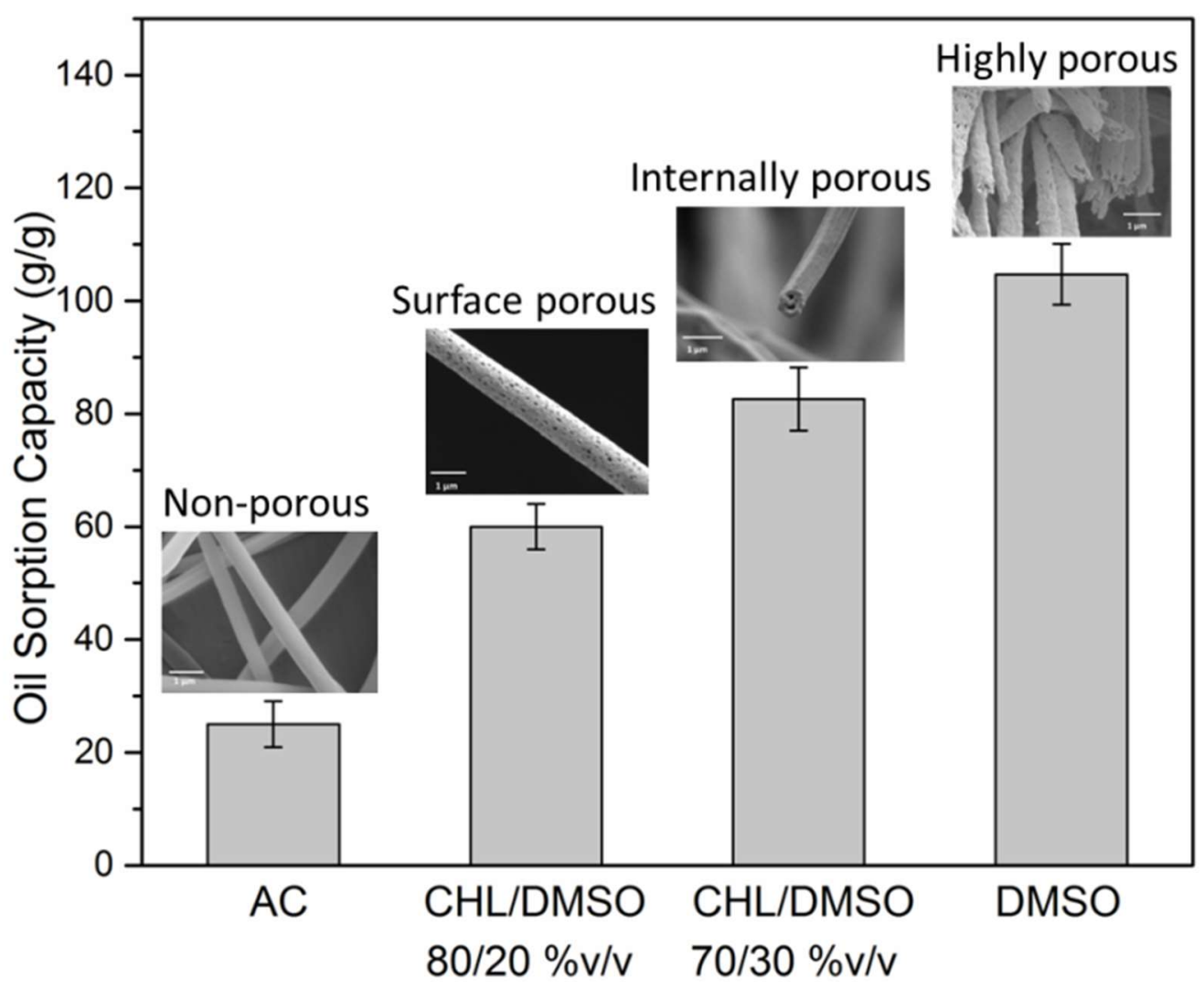

Fig. 12 Mineral oil sorption capacities of PLA fibers with different morphologies after 30s immersion.

\subsubsection{Oil-water separation}

A grade of white mineral oil (Whitemore WOM 65) was dyed with an oil-soluble pigment (Bestoil Green FYG) to increase its visibility. A drop of oil was added to water in a petri dish and due to its lower density $\left(0.88 \mathrm{~g} / \mathrm{cm}^{3}\right.$ at $\left.25^{\circ} \mathrm{C}\right)$ the oil floated on the water surface (Fig. 13a). A porous PLA mat was used to absorb the oil. After sorption of the oil, the mat changed from white to orange (Fig. 13b, $\mathrm{c}$ and d) clearly demonstrating that most of the mineral oil was absorbed by the porous PLA fibre mat after about 30s. 
The hydrophobicity of the electrospun PLA fibres was measured by the contact angle of water droplets on the surface of PLA fibre mats. The results show that PLA melt blend sheet has a low contact angle of $66 \pm 1^{\circ}$, indicating the hydrophilicity. However, the non-porous PLA fibres from AC showed a high contact angle of $132 \pm 0.9^{\circ}$, and the porous PLA fibres show a higher contact angle of $136 \pm 0.8^{\circ}$, which confirms that the fibres are quite hydrophobic due to high specific surface area (see supporting information Fig. S4). The oil-water separation demonstration and contact angle testing results demonstrate that the porous PLA fibres could be used for oil-water separation and clean-up of oil spill on water.
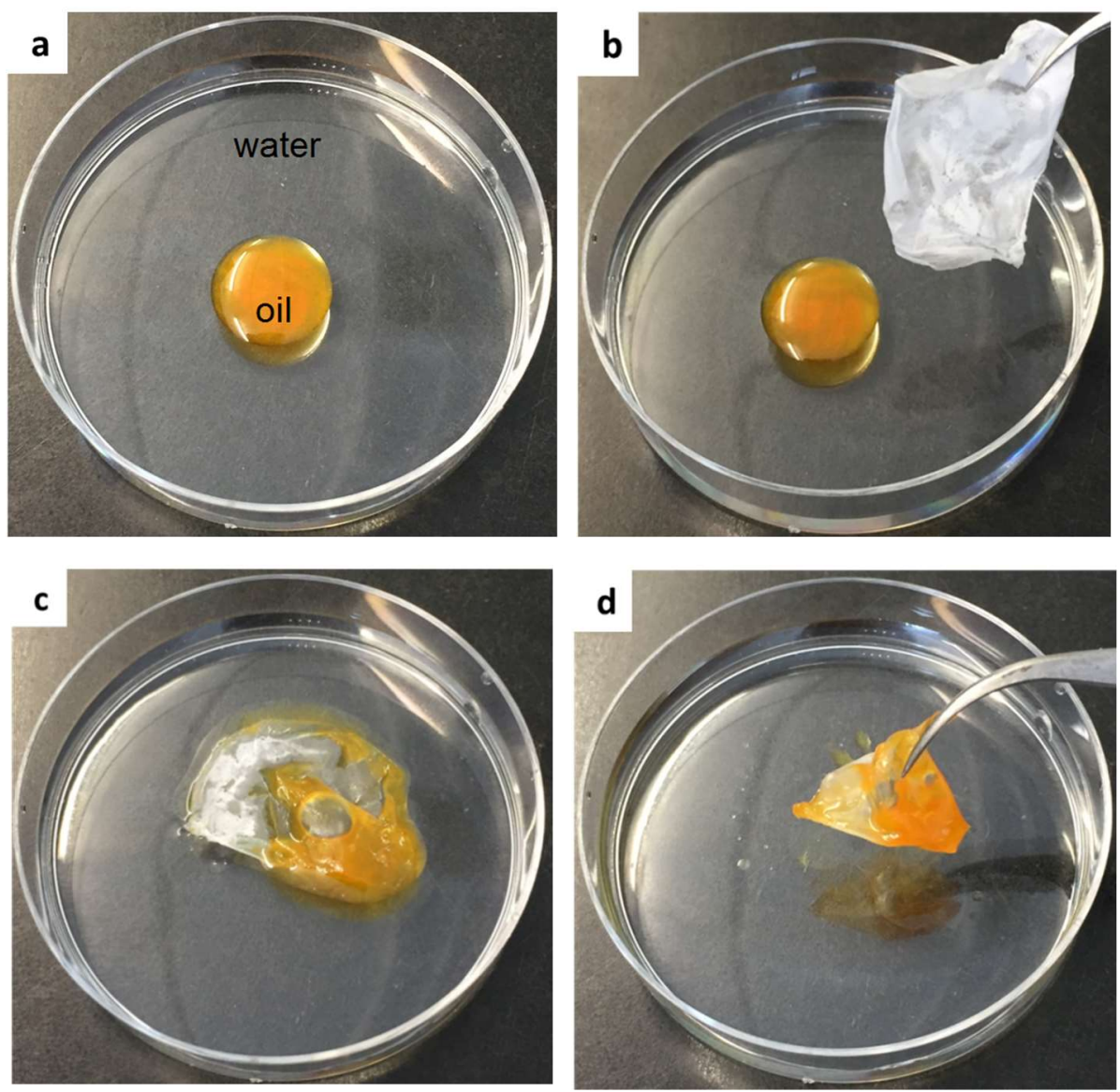

Fig. 13 Demonstration showing that porous PLA fibres can be used for oilwater separation: (a) Oil droplet on water surface (mineral oil dyed with oil based pigment), (b) White fibre mat before oil sorption, (c) Oil sorption by fiber, (d) Most mineral oil removed from water surface and transferred to the fibre mat.

\section{Conclusions}

This paper investigates the different mechanisms whereby porous fibres can be electrospun from poly(lactic acid). By appropriate choice of solvent system, and under suitable environmental conditions with humidity of $50-55 \%$, it is possible to achieve surface porosity, internal porosity or a combination of both. 
Using chloroform, which is a volatile solvent that is immiscible with water, it is found that circular pores of around 100nm are formed on the surfaces of the PLA fibres, due to the so-called 'breath figure' mechanism. Water molecules condense into droplets on the surface due to evaporative cooling of the solvent and these water droplets leave behind circular pores after evaporation.

Porosity can be modified by mixing a water miscible non-solvent (or poor solvent) with the chloroform. By choosing a volatile non-solvent, ethanol, surface porosity can be obtained by a non-solvent induced phase separation (NIPS) mechanism. The nature of this porosity changes depending on the concentration of ethanol in solution from elliptical surface pores $\rightarrow$ scalloped surface $\rightarrow$ smooth fibres with some wrinkles, as the ethanol concentration is increased from $5 \%$ to $30 \%$. Selection of a poor solvent with a high boiling point, i.e. dimethyl sulphoxide (DMSO), to mix with the chloroform, produces internal porosity inside the PLA fibres - also by the NIPS mechanism.

Finally, by dissolving PLA in DMSO (which can be achieved at $80^{\circ} \mathrm{C}$ ) and using this as the spinning solution, porosity is achieved throughout the fibres. This formation of highly porous electrospun fibres is attributable to the vapour induced phase separation (VIPS) mechanism, in which the single solvent is miscible with water and has a high boiling point.

This paper explains how to tailor the porosity of PLA fibres by selection of an appropriate solvent/non-solvent mixture under suitable conditions of humidity. The highly porous fibres showed improved oil absorption capacity which can be used for oil-water separation. The highly porous, biocompatible PLA fibres have potential for use in biomedical applications, such as controlled and effective drug delivery, wound healing and tissue engineering.

\section{Acknowledgements}

The authors are grateful for funding for this work and provision of laboratory facilities from the Department of Materials, Loughborough University, UK. Also they would like to acknowledge technical assistance from Dr Keith Yendall for scanning electron microscopy (SEM) and Dr Elisa Mele for helpful discussions.

\section{References}

[1] Z.M. Huang, Y.Z. Zhang, M. Kotaki, S. Ramakrishna, A review on polymer nanofibers by electrospinning and their applications in nanocomposites, Compos. Sci. Technol. 63 (2003) 2223-2253.

[2] D. Li, Y. Xia, Electrospinning of nanofibers: Reinventing the wheel?, Adv. Mater. 16 (2004) 1151-1170.

[3] S. Agarwal, A. Greiner, J.H. Wendorff, Functional materials by electrospinning of polymers, Prog. Polym. Sci. 38 (2013) 963 - 991.

[4] H.T. Zhu, S.S. Qiu, W. Jiang, D.X. Wu, C.Y. Zhang, Evaluation of Electrospun Polyvinyl Chloride/Polystyrene Fibers as Sorbent Materials for Oil Spill Cleanup, Environ. Sci. 
Technol. 45 (2011) 4527- 4531.

[5] Y. Dong, J. Kong, S. L. Phua, C. Zhao, N. L. Thomas, X. Lu, Tailoring Surface Hydrophilicity of Porous Electrospun Nanofibers to Enhance Capillary and Push-Pull Effects for Moisture Wicking, ACS Applied Materials \& Interfaces, 6 (2014) 14087-14095.

[6] K. Ghosal, M.S. Latha, S. Thomas, Poly(ester amides) (PEAs) - Scaffold for tissue engineering applications, Eur. Polym. J. 60 (2014) 58-68.

[7] A. Abdal-hay, A. Memic, K.H. Hussein, Y.S. Oh, M. Fouad, F.F. Al-jassir, H. Woo, Y. Morsi, X. Mo, S. Ivanovski, Rapid Fabrication of Highly Porous and Biocompatible Composite Textile Tubular Scaffold for Vascular Tissue Engineering, Eur. Polym. J. (2017).

[8] I. Bonadies, L. Maglione, V. Ambrogi, J.D. Paccez, L.F. Zerbini, L.F. Rocha e Silva, N.S. Picanço, W.P. Tadei, I. Grafova, A. Grafov, C. Carfagna, Electrospun core/shell nanofibers as designed devices for efficient Artemisinin delivery, Eur. Polym. J. 89 (2017) 211-220.

[9] H.Y. Li, Y.C. Xu, H. Xu, J. Chang, Electrospun membranes: control of the structure and structure related applications in tissue regeneration and drug delivery, J. Mater. Chem. B. 2 (2014) 5492-5510.

[10] M. Srinivasarao, D. Collings, A. Philips, S. Patel, Three-Dimensionally Ordered Array of Air Bubbles in a Polymer Film, Science. 292 (2001) 79-83.

[11] U.H.F. Bunz, Breath figures as a dynamic templating method for polymers and nanomaterials, Adv. Mater. 18 (2006) 973-989.

[12] M. Hernández-Guerrero, M.H. Stenzel, Honeycomb structured polymer films via breath figures, Polym. Chem. 3 (2012) 563.

[13] J. Zheng, H. Zhang, Z. Zhao, C.C. Han, Construction of hierarchical structures by electrospinning or electrospraying, Polymer, 53 (2012) 546-554.

[14] G.T. Kim, J.S. Lee, J.H. Shin, Y.C. Ahn, Y.J. Hwang, H.S. Shin, J.K. Lee, C.M. Sung, Investigation of pore formation for polystyrene electrospun fiber: Effect of relative humidity, Korean J. Chem. Eng. 22 (2005) 783-788.

[15] C.H. Kim, Y.H. Jung, H.Y. Kim, D.R. Lee, N. Dharmaraj, K.E. Choi, Effect of collector temperature on the porous structure of electrospun fibers, Macromol. Res. 14 (2006) 5965.

[16] Y. Li, C.T. Lim, M. Kotaki, Study on structural and mechanical properties of porous PLA nanofibers electrospun by channel-based electrospinning system, Polymer, 56 (2015) 572-580.

[17] J.T. McCann, M. Marquez, Y. Xia, Highly porous fibers by electrospinning into a cryogenic liquid, J. Am. Chem. Soc. 128 (2006) 1436-1437.

[18] Y.Z. Zhang, Y. Feng, Z.M. Huang, S. Ramakrishna, C.T. Lim, Fabrication of porous electrospun nanofibres, Nanotechnology. 17 (2006) 901-908.

[19] K.A.G. Katsogiannis, G.T. Vladisavljević, S. Georgiadou, Porous electrospun polycaprolactone (PCL) fibres by phase separation, Eur. Polym. J. 69 (2015) 284-295. 
[20] Z. Qi, H. Yu, Y. Chen, M. Zhu, Highly porous fibers prepared by electrospinning a ternary system of nonsolvent/solvent/poly(I-lactic acid), Mater. Lett. 63 (2009) 415-418.

[21] Y. Yang, A. Centrone, L. Chen, F. Simeon, T. Alan Hatton, G.C. Rutledge, Highly porous electrospun polyvinylidene fluoride (PVDF)-based carbon fiber, Carbon, 49 (2011) 33953403.

[22] T.T.T. Nguyen, C. Ghosh, S.G. Hwang, N. Chanunpanich, J.S. Park, Porous core/sheath composite nanofibers fabricated by coaxial electrospinning as a potential mat for drug release system, Int. J. Pharm. 439 (2012) 296-306.

[23] H. Fashandi, M. Karimi, Pore formation in polystyrene fiber by superimposing temperature and relative humidity of electrospinning atmosphere, Polymer, 53 (2012) 5832-5849.

[24] C.L. Pai, M.C. Boyce, G.C. Rutledge, Morphology of porous and wrinkled fibers of polystyrene electrospun from dimethylformamide, Macromolecules. 42 (2009) 2102-2114.

[25] P. Lu, Y. Xia, Maneuvering the internal porosity and surface morphology of electrospun polystyrene yarns by controlling the solvent and relative humidity, Langmuir, 29 (2013) 7070-7078.

[26] L. Li, Z. Jiang, M. Li, R. Li, T. Fang, Hierarchically structured PMMA fibers fabricated by electrospinning, RSC Adv. 4 (2014) 52973-52985.

[27] P.Y. Chen, S.H. Tung, One-Step Electrospinning to Produce Nonsolvent-Induced Macroporous Fibers with Ultrahigh Oil Adsorption Capability, Macromolecules. 50 (2017) 2528-2534.

[28] K. Nayani, H. Katepalli, C.S. Sharma, A. Sharma, S. Patil, R. Venkataraghavan, Electrospinning combined with nonsolvent-induced phase separation to fabricate highly porous and hollow submicrometer polymer fibers, Ind. Eng. Chem. Res. 51 (2012) 17611766.

[29] H.R. Pant, M.P. Neupane, B. Pant, G. Panthi, H.J. Oh, M.H. Lee, H.Y. Kim, Fabrication of highly porous poly ( $\varepsilon$-caprolactone) fibers for novel tissue scaffold via water-bath electrospinning, Colloids Surfaces B Biointerfaces. 88 (2011) 587-592.

[30] P. van de Witte, P.J.J. Dijkstra, J.W. a. W. a van den Berg, J. Feijen, Phase separation processes in polymer solutions in relation to membrane formation, J. Memb. Sci. 117 (1996) 1-31.

[31] Y. Cheng, S. Deng, P. Chen, R. Ruan, Polylactic acid (PLA) synthesis and modifications: A review, Front. Chem. China. 4 (2009) 259-264.

[32] I. S. Bayer, Thermomechanical properties of polylactic acid-graphene composites: A state-of-the-art review for biomedical applications, Materials (Basel), 10 (2017) 748.

[33] M. Bognitzki, W. Czado, T. Frese, A. Schaper, M. Hellwig, M. Steinhart, A. Greiner, J.H. Wendorff, Nanostructured fibers via electrospinning, Adv. Mater. 13 (2001) 70-72.

[34] S.H. Tan, R. Inai, M. Kotaki, S. Ramakrishna, Systematic parameter study for ultra-fine fiber fabrication via electrospinning process, Polymer, 46 (2005) 6128-6134.

[35] R. Casasola, N.L. Thomas, A. Trybala, S. Georgiadou, Electrospun poly lactic acid (PLA) fibres: Effect of different solvent systems on fibre morphology and diameter, Polymer, 55 (2014) 4728-4737. 
[36] L. Li, R. Hashaikeh, H.A. Arafat, Development of eco-efficient micro-porous membranes via electrospinning and annealing of poly (lactic acid), J. Memb. Sci. 436 (2013) 57-67.

[37] L. Natarajan, J. New, A. Dasari, S. Yu, M.A. Manan, Surface morphology of electrospun PLA fibers: mechanisms of pore formation, RSC Adv. 4 (2014) 44082-44088.

[38] E. Rezabeigi, M. Sta, M. Swain, J. McDonald, N.R. Demarquette, R.A.L. Drew, P.M. Wood-Adams, Electrospinning of porous polylactic acid fibers during nonsolvent induced phase separation, J. Appl. Polym. Sci. 134 (2017) 1-8.

[39] C.J. Luo, M. Nangrejo, M. Edirisinghe, A novel method of selecting solvents for polymer electrospinning, Polymer. 51 (2010) 1654-1662.

[40] C.J. Luo, E. Stride, M. Edirisinghe, Mapping the influence of solubility and dielectric constant on electrospinning polycaprolactone solutions, Macromolecules. 45 (2012) 4669-4680.

[41] S. Sato, D. Gondo, T. Wada, S. Kanehashi, K. Nagai, Effects of various liquid organic solvents on solvent-induced crystallization of amorphous poly(lactic acid) film, J. Appl. Polym. Sci. 129 (2013) 1607-1617.

[42] Barton A.F.M., Handbook of Solubility Parameters and Other Cohesion Parameters, CRC Press, Boca Raton, Florida, 1983.

[43] R. Casasola, N.L. Thomas, S. Georgiadou, Electrospinning of poly(lactic acid): Theoretical approach for the solvent selection to produce defect-free nanofibers, J. Polym. Sci. Part B Polym. Phys. 54 (2016) 1483-1498.

[44] A. K. Moghe, B.S. Gupta, Co-axial Electrospinning for Nanofiber Structures: Preparation and Applications, Polym. Rev. 48 (2008) 353-377.

[45] K. Zhang, X. Wang, D. Jing, Y. Yang, M. Zhu, Bionic electrospun ultrafine fibrous poly(Llactic acid) scaffolds with a multi-scale structure., Biomed. Mater. 4 (2009) 35004.

[46] A. Venault, Y. Chang, D. Wang, D. Bouyer, A Review on Polymeric Membranes and Hydrogels Prepared by Vapor-Induced Phase Separation Process, Polym. Rev. 53 (2013) 568-626.

[47] A. Arinstein, E. Zussman, Electrospun polymer nanofibers: Mechanical and thermodynamic perspectives, J. Polym. Sci. Part B Polym. Phys. 49 (2011) 691-707.

[48] H. Chae Park, Y. Po Kim, H. Yong Kim, Y. Soo Kang, Membrane formation by water vapor induced phase inversion, J. Memb. Sci. 156 (1999) 169-178.

[49] H.A. Tsai, C.Y. Kuo, J.H. Lin, D.M. Wang, A. Deratani, C. Pochat-Bohatier, K.R. Lee, J.Y. Lai, Morphology control of polysulfone hollow fiber membranes via water vapor induced phase separation, J. Memb. Sci. 278 (2006) 390-400.

[50] J. Wu, N. Wang, L. Wang, H. Dong, Y. Zhao, L. Jiang, Electrospun porous structure fibrous film with high oil adsorption capacity, ACS Appl. Mater. Interfaces. 4 (2012) 320712. 